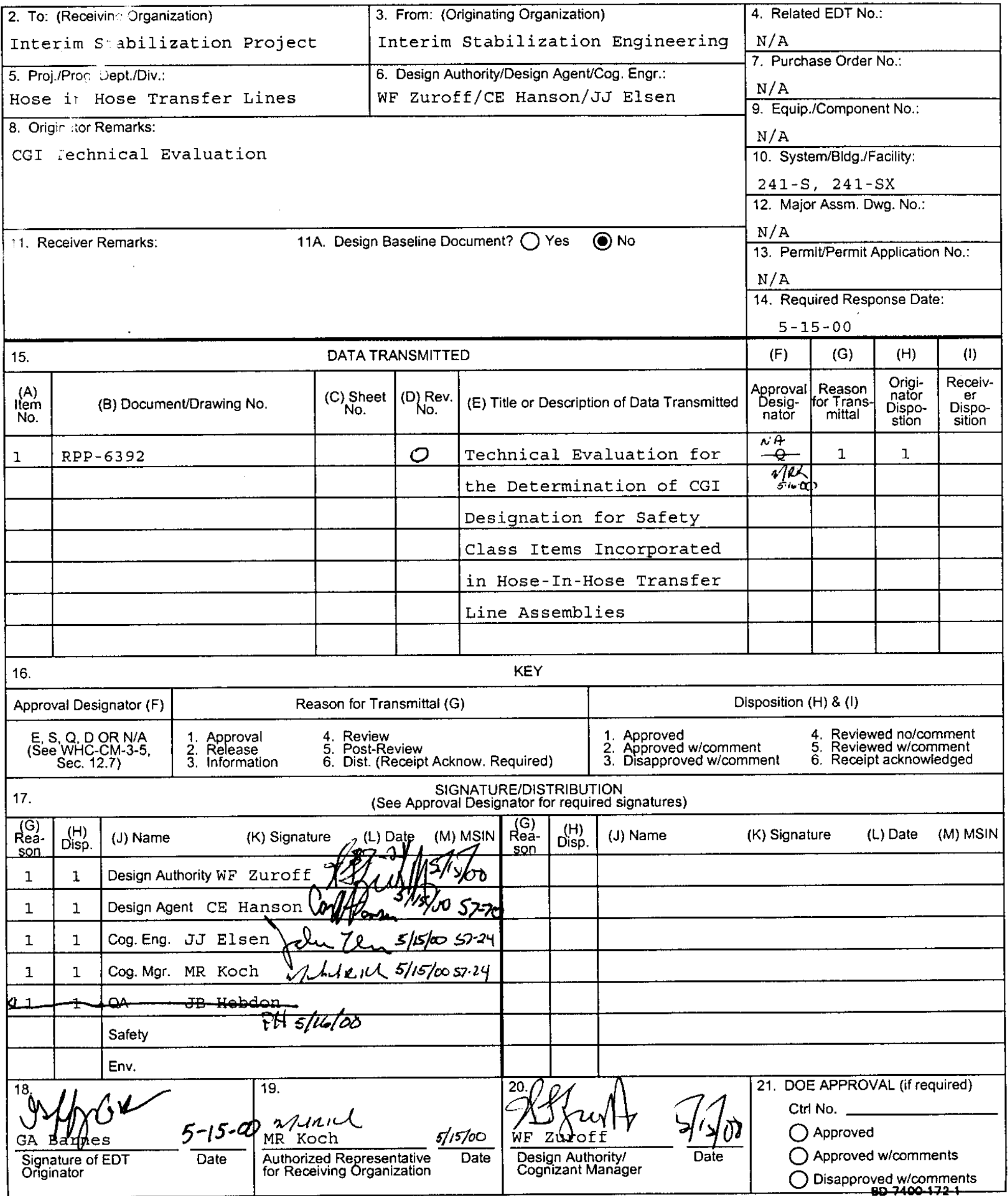




\section{Technical Evaluation for the Determination of CGI Designation for Safety Class Items Incorporated in Hose-In-Hose Transfer Line Assemblies.}

J. R. Buchanan

COGEMA Engineering

Richland, WA 99352

U.S. Department of Energy Contract DE-AC06-99RL14047

$\begin{array}{ll}\text { EDT/ECN: } 629877 & \text { UC: } \\ \text { Cost Center: } & \text { Charge Code: } \\ \text { B\&R Code: } & \text { Total Pages: } \not 4\end{array}$

KeyWords: Commercial Grade Items (CGI), Hose-In-Hose, Engineered Equipment, Transfer Line, Interim Stabilization

Abstract: The purpose of this technical evaluation is to determine whether the secondary hoses are to be categorized as Commercial Grade Items (CGI) or Engineered Equipment. This determination will identify whether or not use of the CGI Dedication process is appropriate.

TRADEMARK DISCLAIMER. Reference herein to any specific commercial product, process, or service by trade name, trademark, manufacturer, or otherwise, does not necessarily constitute or imply its endorsement, recommendation, or favoring by the United States Government or any agency thereof or its contractors or subcontractors.

Printed in the United States of America. To obtain copies of this document, contact: Document Control Services, P.O. Box 950, Mailstop H6-08, Richland WA 99352, Phone (509) 372-2420; Fax (509) 376-4989.
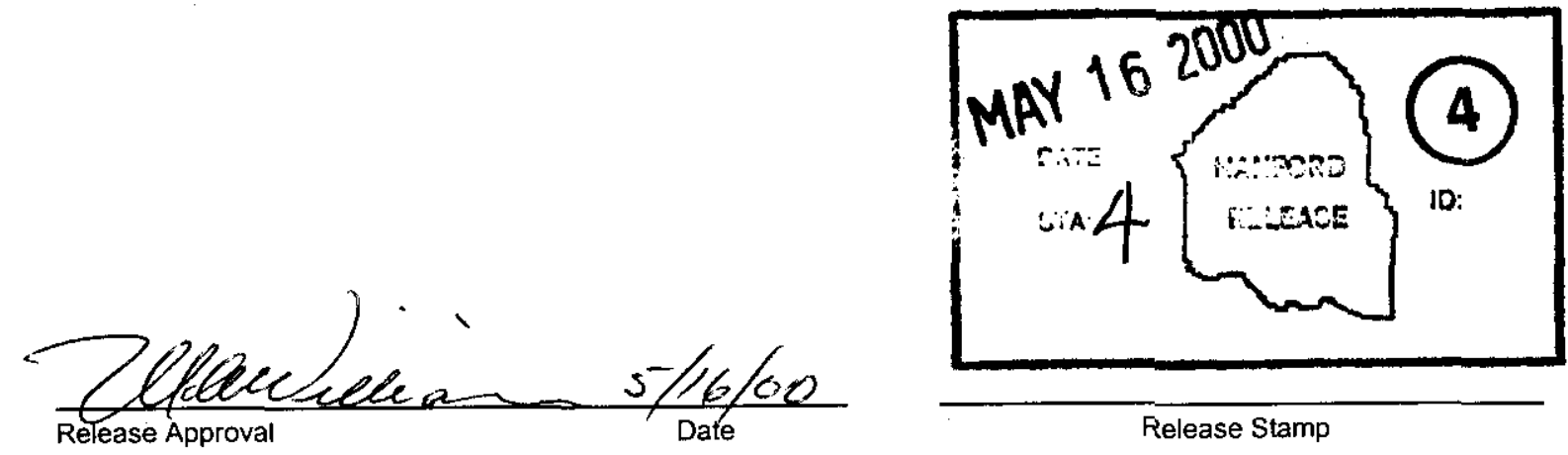

Approved For Public Release 


\section{TECHNICAL EVALUATION FOR THE DETERMININATION OF CGI DESIGNATION FOR SAFETY CLASS ITEMS INCORPORATED IN HOSE-IN-HOSE TRANSFER LINE ASSEMBLIES}

\section{INTRODUCTION}

In order to complete the interim stabilization of Single Shell Tanks (SSTs) in the 241-S and 241SX Tank Farm, all pumpable liquid is to be transferred to safer Double Shell Tanks (DSTs). One element of this activity is to procure and install transfer lines for conveyance of the waste. In order to mitigate risks of release of waste to the environment, and to comply with authorization basis requirements, it is planned to install double encased transfer lines, consisting of a primary hose within a secondary encasement hose. Transfer lines are also to be fitted with appurtenant equipment to control the process temperature of the pumped fluids.

The purpose of this technical evaluation is to determine whether the secondary hoses are to be categorized as Commercial Grade Items (CGI) or Engineered Equipment. This determination will identify whether or not use of the CGI Dedication process is appropriate.

\section{BACKGROUND}

Procurement specification RPP-6028, Hose in Hose Transfer Lines for Hanford's Interim Stabilization Program, was prepared to identify the requirements for the equipment in question. It describes the requirements for all components making up the finished transfer line assemblies, including the secondary hose.

River Bend Hose Specialty, the vendor selected to provide transfer line assemblies complying with the procurement specification, is a manufacturer of hose assemblies serving a wide range of industrial applications. Primary markets served include oil refining, chemical processing plants, and the marine industry.

Typically, River Bend produces hoses "made-to-order" by assembling catalogued hose fittings to catalogued raw hose, which has been cut to length. Often, these assemblies also incorporate additional features to fulfill the client's needs, such as fitting with insulation or utilizing partially conductive materials to prevent static electricity buildup. After assembly, the manufacturer performs a number of tests and inspections to verify the completed assembly will perform its intended function. In most cases, this consists of hydrostatic tests along with visual and dimensional examinations.

As the number of combinations of hose material and hose fittings River Bend normally produces is quite large, they do not have a cataloguing system for preparing an assembly's "part number". Clients typically advise the hose size and material, end connections, and length they desire in procurement documentation. These selections may or may not be at the suggestion of River Bend's manufacturing team. 
This essentially describes the Interim Stabilization Team's planned procurement of commercial grade components. Procurement specification RPP-6028 was prepared to define requirements for double-encased hose-in-hose transfer line assemblies, and the components that make up those assemblies. In this instance, the component of interest is the 4" secondary hose assembly. It is this item, which is to be Safety Class. The safety function of the secondary hose is to provide confinement for a leak from the primary line and route the leak to the various pump or valve pits, which contain leak detectors. Failure of the secondary hose integrity could result in a leak from the primary hose being released to the environment, resulting in a pool leak accident (HNF-SDWM-SAR-O67). The secondary hose is to be laid at grade, with open-end connections installed valve or pump pits. These open-ended connections allow contained leakage to drain into pits. As a consequence of this design, the secondary hose shall not be subjected to appreciable internal pressure, though the hoses themselves will be tested and qualified for use with internal pressures not less than $60 \mathrm{psig}$.

All other items in the final hose-in-hose transfer line assemblies are to be designated general service, as described in HNF-IP-0842, Volume IV, Section 3.11, Commercial Grade Item Upgrade Dedication, paragraph 5.4.4.a.

The 4" secondary hose assemblies planned for use on the Interim Stabilization project are identical in all regards to hose assemblies River Bend manufactures in their normal course of business, without change. They consist of standard catalogued hose material as manufactured by Goodyear Tire \& Rubber, cut to length, and fitted with hose barbs as manufactured by Band-It.

\section{EVALUATION}

This technical evaluation encompasses the requirements included in RPP-PRO-1819, Engineering Requirements. In paragraph 2.4.6, of this document, the criteria, which must be met for an item to be considered commercial grade is identified. These criteria are restated below, along with an appended description of how the secondary hoses planned for use in the Interim Stabilization Program fulfills them.

\section{Criteria 1 - The item is not subject to design or specification requirements that are unique to nuclear facilities.}

Design and specification requirements for the secondary hose are defined by the vendor's normal commercial practices and the requirements of procurement specification RPP-6028. The vendor's normal commercial practices are based on the requirements in RMA IP-2, Rubber Mfrs of America Hose Handbook, a document utilized in a broad range of industrial applications. The standards and design requirements invoked by the procurement specification, RPP-6028, include only national standards which are commonly applied to a broad range of non-nuclear applications. These include: ASME B31.3, Process Piping to define the requirements for end connections and interfaces; ANSI B1.20.1, Pipe Threads to define the requirements for threads which may be used to retain internal pressure; and, NFPA 70, National Electrical Code to define requirements for electrical characteristics of finished assemblies. All standards and design requirements invoked are applicable to industrial applications other than nuclear. 
Criteria 2 - The item is used in applications other than nuclear facilities.

As noted in the background information presented above, the secondary hoses planned for the Interim Stabilization Program are identical in all respects to hose assemblies manufactured for and utilized by other industries, such as chemical processing or refining.

Criteria 3 - The item is ordered from the manufacturer/supplier based on specifications set forth in the manufacturer's published product description (e.g., a catalog or national standard such as American Society for Testing and Materials).

As noted in the background information presented above, the secondary hoses planned for the Interim Stabilization Program are to be ordered in an identical manner as that used by clients in other industries - by using information published by the vendor or sub-tier manufacturers and published national standards. For example, secondary hose end fittings are specified as model number S650 supplied by Band-it Corp. The hose is designated as "Versigard", a trade name used by Goodyear Tire and Rubber. As with all normal commercial procurements from this manufacturer, River Bend shall assemble fittings and hose into a completed element using commercial practices for crimping.

The part number/designation for the Safety Class (SC) components of this procurement (Outer hose components) are:

1. Hose-Goodyear, EPDM (Versigard), 60 psi WP, static dissipating

2. Clamps- 5" $\mathrm{x} 3 / 4$ "W, Band-It JR

Mod no. 546-418-123

3. Hose Nipples- 4", Schedule 40, Tri-Lokt

Cat no. JS215

4. Reducers- Concentric, 8" x 4" Butt Weld, Schedule 40

Cat no. S650

5. Flanges- 8 " Weld neck, Raised Face, Class 150

6. Insulation- Armstrong, Armaflex, Self-Seal

ASME B16.9

ASME B16.5

Type AP

[NOTE: Insulation is not $\mathrm{SC}$, but is wrapped around the $\mathrm{SC}$ components, and is itself commercially available, like the SC items.]

\section{CONCLUSION}

Based on the above evaluation, secondary hoses complying with procurement specification RPP6028 and planned for the Interim Stabilization Program meet all criteria specified in RPP-PRO1819, Engineering Requirements, as well as HNF-IP-0842, Volume IV, Section 5.13, paragraph 4.3 for commercial grade equipment. As such, these items will be procured as commercial grade items and dedicated to safety class upon confirmation that all requirements for dedication are met. 